proposed, being able to make a wise decision, and being free from coercion. In practice most decisions were shared between parents and child, with older children's views being given more weight.

In carrying out this project the researchers were made aware of the amount of suffering children were expected to endure, of failures in communication between staff, parents and patients, and of other causes of distress due to staff attitudes, lack of training or hospital organisations which were not user-friendly. These comments tend to be one-sided, but as they are on the side of the child they are pertinent and need promoting.

RICHARD WEST Medical Postgraduate Department, University of Bristol.

\section{Monitoring the health and rehabilitation of torture survivors}

\author{
S Bøjholm, A Foldspang, M Juhler, \\ M Kastrup, G Skylv, F Somnier, \\ Copenhagen, Rehabilitation and \\ Research Centre for Torture Victims, \\ 1992, 59 pages, $£ 5.00$
}

There are many centres around the world dedicated to the documentation and treatment of torture survivors. Some have been set up within the countries where torture occurs, and personal danger may exist there, both for the workers and the clients, but more centres are in countries where victims seek refuge, and there, while there may be a greater element of safety, the clients have the severe social consequences of exile added to the memories of torture with which they must live. Some centres are almost overwhelmed by the pressure of work while others, more fortunate, are able to select carefully and accept only the most deserving cases into the centre. It is important that all types of centre should organise their work to the best advantage, and this booklet aims to provide guidelines in achieving this.

The Copenhagen-based Rehabilitation and Research Centre for Torture Victims (RCT) is well placed to formulate guidelines, since it has, over a period of ten years, accepted clients from a large number of different cultures, is well funded, and has experience in educating carers in Denmark as well as setting up units in other countries. The centre has published widely in general and specialist journals. On the other hand, cases accepted for treatment at the RCT are very carefully selected and are not taken on until they have gained refugee status in Denmark. The centre must therefore have missed out on some aspects of torture rehabilitation and documentation work, in particular, aspects to do with that large and distressed group, the asylum-seekers.

The first section of the booklet formulates, in language that will appeal to managers more than clinicians, the strategic process and aims for monitoring the work of treatment, publicising and, as an eventual aim, prevention of torture. Section two details production models for rehabilitation of clients, with details of how the individual treatment of each client is recorded, the method of documentation of RCT's consultancy activities, and the resources of the centre, training and library activities. Section three is devoted to definitions of torture activities and symptoms, some of them derived from the DSM-111-R classification, with diagnoses derived from the General ICD-9. In section four there is shown a selection of forms in use at the RCT for each client on preliminary examination, admission and discharge as well as forms providing a social assessment and a sleep record.

It is disappointing that the authors have not added an account of the results of the RCT's work, which would have been of interest to those centres who have no contact with the mainstream and need some yardstick by which to assess their own successes and failures.

This booklet could prove useful for those wishing to set up a new centre or trying to re-organise one that has become chaotic. It is unlikely, though, that many centres will have the time or resources available to take the fullest advantage of all that is set out here.

DUNCAN FORREST

Medical Foundation for the Care of victims of Torture, London

\section{New directions in moral theology: the challenge of being human}

Kevin T Kelly, London, Geoffrey Chapman, 1992, x+164 pages, £10.99
The basic concern of this book is of $\stackrel{\mathbb{2}}{\varrho}$ importance to all readers of the JME, whilst its context is of particular

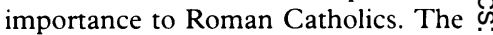
basic concern is with the moral life of human beings; that they should treat $\stackrel{G}{\rightarrow}$ one another with respect. They need to respond to the core of rationality and desires common to humanity, particularly by listening to wise and loving people. This core of human values will be expressed in a variety of ways, and we need to appreciate this diversity, and to realise that a moral pluralism of this kind is not the same as a moral relativism which denies that there are any objective moral truths.

The context of the book is the new directions in moral theology called for by Vatican Council II (1962-1965), one element of which is a dialogue with all men and women of good will. Since the council there has been a vigorous debate among Roman Catholic moral theologians on the nature and depth of these new directions. Kelly is with those who desire a fundamental reconstruction, to achieve a moral theology which is catholic, ecumenical and universal. He draws on his experience both as lecturer in Christian ethics Heythrop College in London Un⿳亠口冋. versity and on pastoral work in deprived area of Liverpool. The dignity of the person is to him a dynamic affirmative in the light of which he explores what it is to be pro-cultural and pro-person (a better term than pro-life). It leads him to explore the concept of the common good, and how social conflicts can be creatively handled in terms of it; for there is no society free of conflicts.

Conflicting opinions are also endemic on particular moral issues. The book begins with two articles in 8 The Times on the day that the House of Commons began the debate on the 0 Human Fertilisation and Embryology Bill; one was by Archbishop Habgood $\frac{D}{2}$ of York and one by Cardinal Hume of Westminster, and they reached oppo- N site conclusions on the legitimacy of embryo research. In exploring how this could happen Kelly shows how moral absolutes cannot fully describe a particular situation, and that the moral life does not mean living by absolute certainties on particular issues, but by making prudent judgements, in the making of which $\frac{0}{0}$ principles and situations influence one $\frac{\vec{D}}{\mathbb{D}}$ another. Risks are involved, and the $\frac{\mathscr{Q}}{\mathscr{T}}$ trickiest issues are those where we $\varrho$ cannot afford the luxury of learning by our mistakes. 